\title{
Investigation of the Crack Propagation in the Graphene/ Synthetic Rubber Nanocomposite Materials with DIC Technique
}

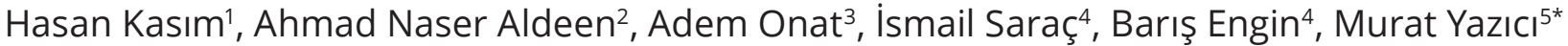 \\ 1 R\&D Center, Emsa Nano Technology Energy Trade Co.,16285 Bursa, Alaaddinbey Mh. 614.Sk 3/16, Turkey \\ 2 Department of Mechanical Engineering, Faculty of Engineering, Istanbul University Cerrahpaşa, 34320 Istanbul, Universite Yolu \\ Bağlariçi, P.O.B. 7, Turkey \\ ${ }^{3}$ Department of Machinery and Metal Technologies, Vocational School of Sakarya, Sakarya University of Applied Sciences, 54290 \\ Sakarya, P.O.B. 3, Turkey \\ ${ }^{4}$ R\&D Center, SKT Spare Parts and Machinery Industry and Trade Co., 16140 Bursa, BOSB Ali Osman Sonmez Bulv. 17., Turkey \\ ${ }^{5}$ Department of Automotive Engineering, Faculty of Engineering, Bursa Uludag University, 16059 Bursa, Gorukle Kampusu, Turkey \\ *Corresponding author, e-mail: myazici@uludag.edu.tr
}

Received: 16 August 2021, Accepted: 21 December 2021, Published online: 27 January 2022

\begin{abstract}
This study investigated the crack propagation behavior of the graphene-reinforced synthetic rubber matrix nanocomposite materials. Graphene-filled rubber conductive nanocomposites developed within the scope of this study were obtained in two stages using mechanical mixers. The relationship between crack propagation and electrical resistance change was investigated using single-edge notched specimens in a tensile tester. Digital image correlation (DIC) technique was used to observe the crack resistance function depending on the local strain distribution. The results from the tests were evaluated to define the relationship between the crack length, the amount of conductive filler, and the change in electrical resistance. The sharp edges of the graphene nanoplatelets negatively affected the fracture resistance of the samples. In addition, it was observed that even at low strain values, gaps were formed in the areas close to the crack tip. The three-dimensional transmission network formed by graphene nanoplatelets dispersed in the matrix improved the electrical conductivity properties of the nanocomposites, so the relationship between crack propagation and electrical resistance change was determined.
\end{abstract}

\section{Keywords}

graphene nanoplatelets, carbon black, hybrid nanocomposites, synthetic rubber, crack propagation, crack initiation, digital image correlation

\section{Introduction}

Using elastomeric materials is widespread because their hyperelasticity made them practical for damping vibrations and producing tires. For that reason, they are often used under dynamic or fatigue conditions; they exhibit a high fracture resistance and long service life. The fracture resistance and material performance of an elastomer material due to crack propagation were not apparent until research by Rivlin and Thomas based on the Griffith theory. They have created more suitable solutions by modifying the irreversibility of energy dissipation in high-stress areas near the crack tip of the elastomeric material [1, 2].

Griffith determined the energy needed to drive a crack through a strained glass sheet and decided that the crack will grow if the released elastic energy is greater than the energy required to form a new fracture surface [3]. The rate of tearing or strain energy release with a given certain displacement $(\Delta)$ is shown in Eq. (1):

$T=-\left(\frac{\partial U}{\partial A}\right)_{\Delta}=-\frac{1}{B}\left(\frac{\partial U}{\partial c}\right)_{\Delta}$,

where $A$ is the area of the new fracture surface, $B$ is the thickness of specimens, $U$ is the stored strain energy, and $c$ is the crack length. The energy criterion, called the $J$-integral value, has recently been studied in many scientific studies to determine the fracture resistance property of the material. Dong et al. [4] used $J$-integral theory for fracture and fatigue properties of silica and carbon black filled rubber composites and obtained the critical $J$ value $\left(J_{I C}\right)$ as 
an indicator of crack initiation resistance and tearing modulus $\left(T_{R}\right)$ values for crack propagation. The study showed that the silica and carbon black (CB) ratio improved both $J_{I C}$ and $T_{R}$ and the addition of silica improved crack initiation and propagation resistance. Agnelli et al. [5] used this criterion to investigate the fracture resistance of hybrid rubbers with different filler content. Samples prepared with different filler ratios were compared using $J_{I C}$, defined as the critical tear energy required per unit to create a new fracture surface, and $T_{R}$ tearing modulus related to crack propagation resistance, which defines the fracture resistance at the initiation stage. They observed that $J_{I C}$ and $T_{R}$ positively correlated with crack resistance at both crack initiation and propagation stages. Yan et al. [6] studied the fatigue fracture performance of the rubber nanocomposites filled by graphene using micro-focus Hard-X-Ray beamline radiation. They mentioned that graphene inclusion had two opposite effects on fracture resistance. The graphene addition at low fatigue strains accelerated the crack growth, whereas it was retarded at high fatigue strains. They attributed that to the compilation between strain-induced crystallization and cavitation at the crack tip.

Dong et al. [7] investigated the effects of carbon nanotubes (CNTs) and carbon black hybrid fillers on the fracture resistance of Styrene-Butadiene Rubber (SBR) composites. They used $J$-integral tests to evaluate crack initiation and propagation resistance. They measured the amount and distribution of strain formed near the crack tip with digital correlation and found that high carbon nanotubes content improved the fracture resistance. Song et al. [8] used silicon rubber as matrix and graphene nanoplatelets (GE) as filler, and obtained composite mixtures with improved thermal, electrical, and mechanical properties. The electrical conductivity of the mixture improved with increasing GE content. In addition, even the addition of graphene nanoplatelets at a low filler ratio (i.e., $8 \%$ ) improved the mechanical properties and resulted in approximately $153 \%$ improvement in tensile strength. Liu et al. [9] used the 2D digital image correlation (DIC) method to measure the deformation of soft and deformable dual-crosslink hydrogel (polyvinyl alcohol) ) in the strain field in tension-loaded samples containing a central hole, a circular edge notch, and a sharp crack. The results have confirmed the accuracy of DIC for measuring the high strain gradient of the specimen in the presence of large deformation. Rossi et al. [10] investigated the deformation behavior of materials with high ductile and anisotropic properties in the contraction region by using the Stereo-DIC technique and an interpolation method based on bezier curves with experiments on flat and cylindrical geometries. The numerical models used to validate the method have been verified by actual experiments. Le Cam et al. [11] addressed the fatigue damage in carbon black filled natural rubber under uniaxial and multiaxial loading conditions. They considered fatigue damage both on a macroscopic and microscopic scale and showed that the cracks started from microstructural defects with an average diameter not exceeding $400 \mu \mathrm{m}$ and that the onset of cracks on a macroscopic scale corresponded to crack growth on a microscopic scale.

The use of full-field optical techniques to measure materials' displacement and surface deformation has recently increased significantly. Digital image correlation (DIC) is a measurement technique widely used in experimental mechanics because its advantages include non-contact, fullarea optical measurement, high sensitivity, no special environmental requirements, and easy handling [12-15]. In this method, the deformation carrier is the tracking speckle patterns sprayed on the material surface or the area of interest. The relative displacements between an undeformed reference image and the deformed image are recorded by optical methods according to a specific algorithm. As long as the material surface measured with DIC can be patterned and visualized correctly, it can allow large-scale deformation studies [16]. In this study, full-field strain in the area near the crack tip was obtained by Ncorr software [17], an opensource software. The results from Ncorr are in good agreement with those from the Vic 2D [18] software.

This study investigated the improved electrical conductivity properties of graphene-filled rubber nanocomposites [19] and the propagation properties of cracks in test specimens with a single edge notch. DIC technique was used to observe the crack resistance function depending on the local strain distribution. It was determined that the $J_{I C}$ and $T_{R}$ values decreased with the increase in the amount of conductive graphene filler in the nanocomposite mixtures. The relationship between the crack length and the electrical resistance change due to the amount of graphene filler is determined by measuring.

\section{Experimental}

\subsection{Production and materials}

The matrix components of the mixture were two types of synthetic rubber, chloroprene rubber (CR) with the trade name Baypren $^{\circledR} 210$ and polybutadiene rubber (PBR) with the trade name CBR 1203 obtained from Metekim A. Ş., Turkey. 
The carbon black $(\mathrm{CB})$ used in the mixture as a primary filler material (N-660 General purpose furnace (GPF), pour density $440 \pm 40 \mathrm{~kg} / \mathrm{m} 3$, ash content $<0.7 \%$, heating loss $<1.5 \%$, cetyltrimethylammonium bromide (CTAB) surface area $29 \sim 43 \mathrm{~m}^{2} / \mathrm{g}$, nitrogen adsorption specific surface area 29 41 $\mathrm{m}^{2} / \mathrm{g}$, iodine adsorption ratio $36 \pm 6 \mathrm{~g} / \mathrm{kg}$ ), was purchased from Anlaş Lastik Co., Turkey. The CB filler has high tensile stress, excellent processing performance, high rebound performance, and high flexibility. The graphene (GE), (bulk density $0.45 \mathrm{~g} / \mathrm{cm}^{3}$, specific surface area $170 \mathrm{~m}^{2} / \mathrm{g}$, number of layers $5-10$, averagely $30 \mu \mathrm{m}$ diameter, dimensions (X\&Y) 5-10 $\mu \mathrm{m}$, thickness (Z) 5-10 nm and purity $\sim 99.9 \%$, conductivity $1100-1600 \mathrm{~S} / \mathrm{m}$, and gray color), was obtained from Nanografi Co., Turkey. Two-dimensional planar GEs have been used to increase the rubber blend's thermal and electrical conductivity, stability, and barrier properties. Zinc oxide ( $\mathrm{ZnO})$, stearic acid, hydrocarbon resin (C100-GA), octylated-diphenylamine (ODPA), N-isopropyl-N'-phenyl-pphenylenediamine (IPPD), antilux 654, vulkanox 4020, magnesium oxide (MgO), min. 90\% insoluble sulfur (IS 90-65), N,N'-ethylene thiourea (ETU 80) are all commercially available products. The aromatic oil used to prepare the compound (density @ $29.5^{\circ} \mathrm{C} \cdot \mathrm{gm} / \mathrm{ml}, 0.99$ ) was obtained from Panama Petrochem Ltd., India. The formulation of the rubber mixtures prepared with graphene nanoplatelets in different filler ratios [20] is given in Table 1. All materials are included in the mix as parts per hundred rubber (phr).

The GE-filled rubber nanocomposites (nGRs) were prepared in two steps using closed and open mixers in Anlaş Lastik Co.'s production line. The rubber group (Baypren ${ }^{\circledR}$

Table 1 The formulation of hybrid nanocomposites (amount in phr)

\begin{tabular}{llcccc}
\hline \multirow{2}{*}{ Compound contents } & \multicolumn{4}{c}{ Samples } \\
\cline { 2 - 6 } Rubber & Baypren 210 & 80 & 80 & 80 & 80 \\
groups & CBR 1203 & 20 & 20 & 20 & 20 \\
Filler & N-660 GPF & 47.6 & 47.6 & 47.6 & 47.6 \\
groups & Graphene & 0 & 1 & 4 & 8 \\
& ZnO & 4 & 4 & 4 & 4 \\
& Stearic Acid & 0.25 & 0.25 & 0.25 & 0.25 \\
& C 100-GA & 6 & 6 & 6 & 6 \\
Chemicals & ODPA & 1 & 1 & 1 & 1 \\
& IPPD & 1 & 1 & 1 & 1 \\
& Antilux 654 & 1 & 1 & 1 & 1 \\
& Vulkanox 4020 & 1 & 1 & 1 & 1 \\
& MgO & 4 & 4 & 4 & 4 \\
Oil & Aromatic Oil & 20.34 & 20.34 & 20.34 & 20.34 \\
& IS 90-65 & 0.5 & 0.5 & 0.5 & 0.5 \\
& ETU 80 & 0.35 & 0.35 & 0.35 & 0.35 \\
\hline
\end{tabular}

210 and CBR 1203) was softened and plasticized in a closed laboratory mixer in the first stage. The $\mathrm{CB}$, chemicals, and aromatic oil required for the nGR-0 mixture were added to the rubber matrix and mixed in a closed mixer at $105{ }^{\circ} \mathrm{C}$ for 40 minutes. The plasticization time of the rubber group, the order in which other recipe materials are added to the mixture, and the mixing times are the same in all mixtures. Process conditions such as rotor speeds and mixing temperatures of the closed mixer are automatically recorded. In the first stage, vulcanizer chemicals called IS 90-65 and ETU 80 were not added to the mixture. After the mixtures obtained at this stage were kept at $23 \pm 2{ }^{\circ} \mathrm{C}$ and $50 \% \pm 5 \%$ relative humidity for 24 hours according to ASTM D471-12 standard [21], the second stage was started. The second stage was carried out in a two-cylinder open mixer. First, the distance between the open-roll mixer rollers was set to $5 \mathrm{~mm}$. The vulcanizer group chemicals were added to the mixture at this stage. The second step was carried out at $70{ }^{\circ} \mathrm{C}$ and $40 \mathrm{rpm}$ roller speed for 25 minutes. After the material coming out of the open mixer was drawn to a size of $40 \times 5 \mathrm{~mm}$ (width $x$ thickness), it was kept in a laboratory environment at $23 \pm 2{ }^{\circ} \mathrm{C}$ and $50 \% \pm 5 \%$ relative humidity for 24 hours.

\subsection{Preparing specimens}

Rubber plates of $150 \times 150 \times 2 \mathrm{~mm}$ dimensions were produced for mechanical and electrical tests. For compression and hysteresis tests, $\varnothing 29 \times 12.7 \mathrm{~mm}$ samples were prepared following ASTM D395-18 [22]. Tensile and hysteresis test samples to be used in the mechanical tests of the mixtures were vulcanized in a laboratory-type vulcanization press with a capacity of 30 tons. Before the pieces were cured in the molds, $0.0001 \mathrm{~g}$ were weighed on a precision balance and then cured. Test plates were prepared by curing for 8 minutes at $165^{\circ} \mathrm{C}$. All of the prepared test plates were kept at room conditions for a minimum of 16 hours and then tested. For each test, a minimum of 5 samples was prepared and tested. In determining sample sizes, the connection status of the probes used in electrical resistance measurements to the test sample and the ease of mounting to the Tensile test machine (Zwick/Roell Z010, Germany) were considered. The specimen dimensions determined for the resistance measurement tests are $100 \times 15 \times 1.95 \mathrm{~mm}$ $(\mathrm{L} \times \mathrm{W} \times \mathrm{T})$ and are shown in Fig. 1 .

A particular cutting mold was produced for the test samples, and the cutting process was carried out in a sample cutting press with a capacity of $15 \mathrm{kN}$. The cutting process was done in one motion and without a notch 


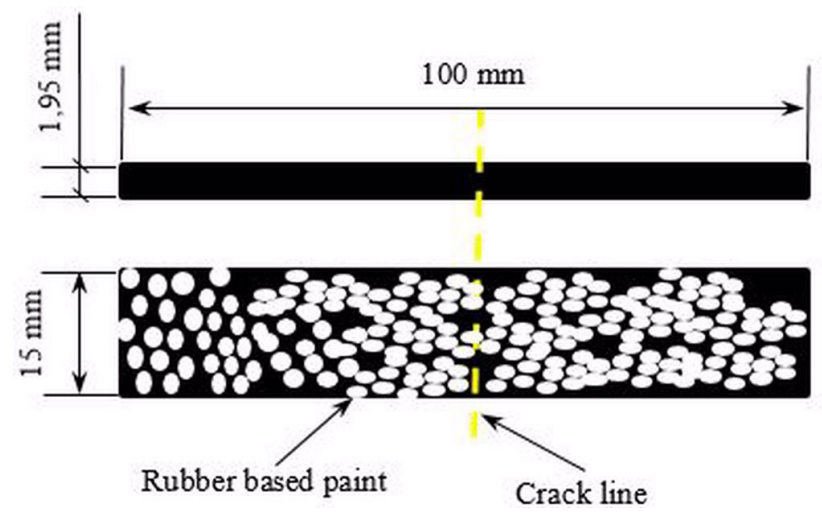

Fig. 1 Schematic diagram of the dimensions of the test sample

effect. All surfaces of the cut samples were checked with a Zeiss Stemi 508 stereo microscope. Proper speckling on the region of interest (ROI) [23] of the sample is required to implement DIC analyzes. The regular paint does not have the hyperelasticity the samples have, so to ensure that spackles tracking was implying material tracking, the rubber-based paint was prepared and sprayed on ROI. Rubber-based paints were prepared by dissolving rubber latex suitable for $\mathrm{nGr}$ formulation in some solvent, adding accelerator, $\mathrm{ZnO}$, sulfur, paint pigment, and vulcanizer and mixing at $500 \mathrm{rpm}$ for 30 minutes with the help of an air-pneumatic mixer, and kept at room temperature for 24 hours. The speckling operation was implemented randomly and differently in density to dedicate the singularity of grayscale level every subset of ROI should have [24]. The paint applied to the samples was kept in an oven at $45{ }^{\circ} \mathrm{C}$ for 15 minutes (Binder, Germany) to ensure that it adhered to the sample surface as vulcanized.

\subsection{Characterization and tests}

The rheology graphics of the viscoelastic properties of the mixtures during curing were obtained with the MDR 3000 (Montech, Germany) rheometer tester in 8 minutes at $165^{\circ} \mathrm{C}$, according to the ASTM D5289-19a standard [25]. The densities of the samples were measured with analytical precision balance (AND GR-200, Japan) according to ASTM D297-15 [26]. The hardness of vulcanized nGr nanocomposite samples (Shore A) was measured by Zwick/Roell 3130 (Germany) hardness tester according to ASTM D2240-00 standard [27]. Tensile tests of cured nGr samples were measured on a tensile testing machine (Zwick/Roell Z010, Germany) at $200 \mathrm{~mm} / \mathrm{min}$ crosshead speed by cutting dumbbell test specimens from a $2 \mathrm{~mm}$ thick test plates according to ASTM D412-15 standard [28]. The hysteresis tests were carried out on a tensile testing machine (Zwick/Roell Proline Z010 TH, Germany) at a constant test speed of $15 \mathrm{~mm} / \mathrm{min}$. The Scanning electron microscope (SEM) analysis studies were carried out in Tubitak Butal Laboratory, Bursa, with Vega3 Tezcan branded Scanning electron microscope (SEM-EDX). $20 \mathrm{kV}$ acceleration voltage was used in the studies. All samples were coated with Au of 3-5 nm thickness for better imaging before analysis. The electrical conductivity of graphene-filled rubbers is increased with the coating.

\subsection{J-integral test}

The J-integral criterion was conducted to investigate the crack propagation and initiation resistance during quasi-static loading [5, 29-31]. The gauge length $\left(\mathrm{L}_{0}\right)$ was $76 \mathrm{~mm}$ regarding the distance needed to hang the electrical probes using a surgical scalpel $(0.45 \mathrm{~mm})$, several specimens differ in the length of pre-cut were prepared for each sample (i.e., $1 \mathrm{~mm}, 3 \mathrm{~mm}, 5 \mathrm{~mm}, 7 \mathrm{~mm}, 10 \mathrm{~mm}$ ). The single edge notched test (SENT) was implemented, utilizing Zwick/Roell Z010 tensile test machine with a crosshead speed of about $20 \mathrm{~mm} / \mathrm{min}$ and room temperature. $J$-integral vs. displacement curve was drawn, investing the tearing energy or $J$-integral identified by Eq. (1) [5], see Fig. 2. Crack propagation resistance, contrary to old assumptions, and the part defined as Crack tip opening displacement (CTOD) was investigated using an indirect pointer, since CTOD values less than $0.1 \mathrm{~mm}$ were challenging to observe, a CTOD value of $0.1 \mathrm{~mm}$ was accepted as the onset of the crack [6].

CTOD growth was tracked by a Sony $\alpha 6000$ digital camera set in front of the crack [32-34]. The global displacements corresponding to CTOD of $0.1,0.2,0.3$, 0.4 , and $0.5 \mathrm{~mm}$ were recorded, as shown in Fig. 3. The

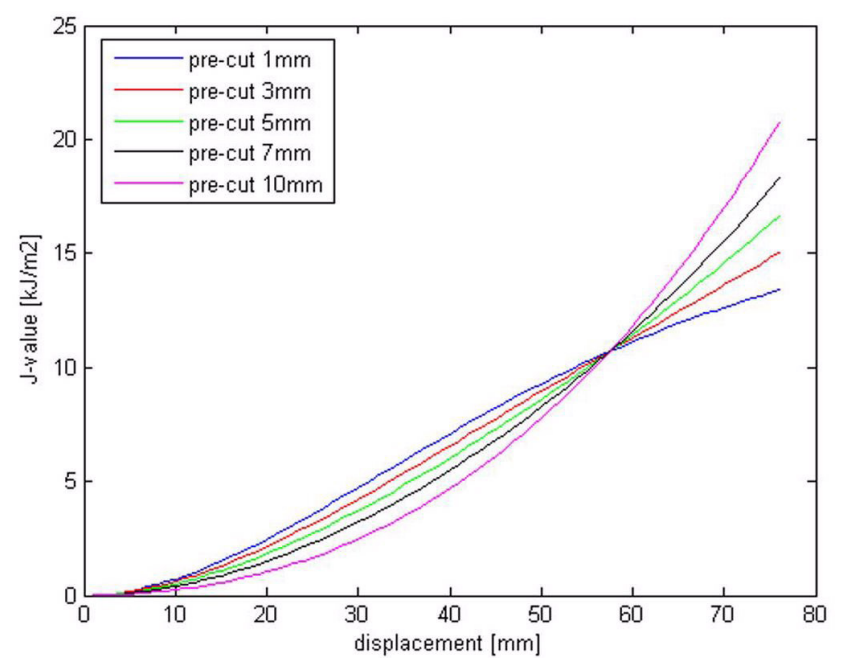

Fig. $2 J$ value vs displacement curves for nGr-1 and all pre-cut lengths 

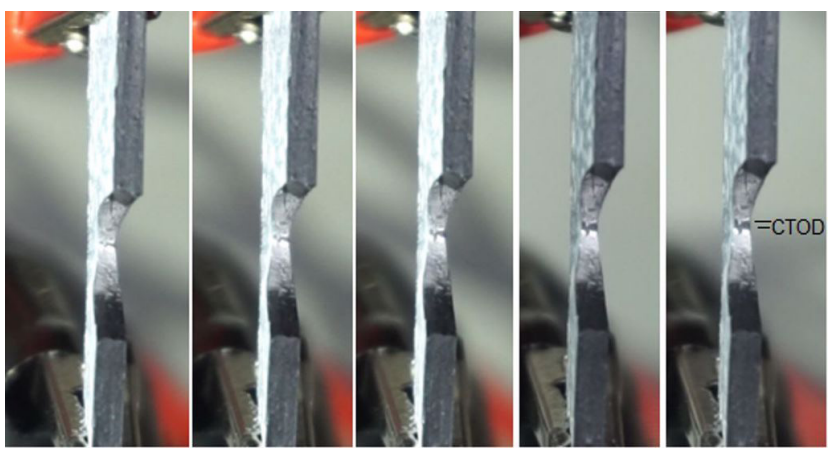

Fig. 3 CTOD growth from $0.1 \mathrm{~mm}$ to $0.5 \mathrm{~mm}$

$J$-integral values corresponding to the CTOD values characterizing the relationship between the $J$ value and CTOD growth are shown in Fig. 4.

$T_{R}=\frac{d(J \text { value })}{d(\mathrm{CTOD})}$

The $J$ value versus CTOD curve slope at low strains (between CTOD values of 0.1 and $0.5 \mathrm{~mm}$ ) is $T_{R}$ the tearing modulus according to Eq. (2) [7].

It has been mentioned earlier that the CTOD is considered $0.1 \mathrm{~mm}$ as crack initiation. Also, the corresponding $J$ value is $J_{I C}$, which is the critical energy per unit required to propagate the crack [15].

\subsection{Strain energy density}

Strain energy density is pretty associated with fracture resistance in general. The area under stress vs. strain curve describes the strain energy density stored by the unit of volume of material up to a specific strain. The test was executed adopting specimens with a pre-cut of $3 \mathrm{~mm}$. The specimens were tested by stretching to $100 \%$ strain.

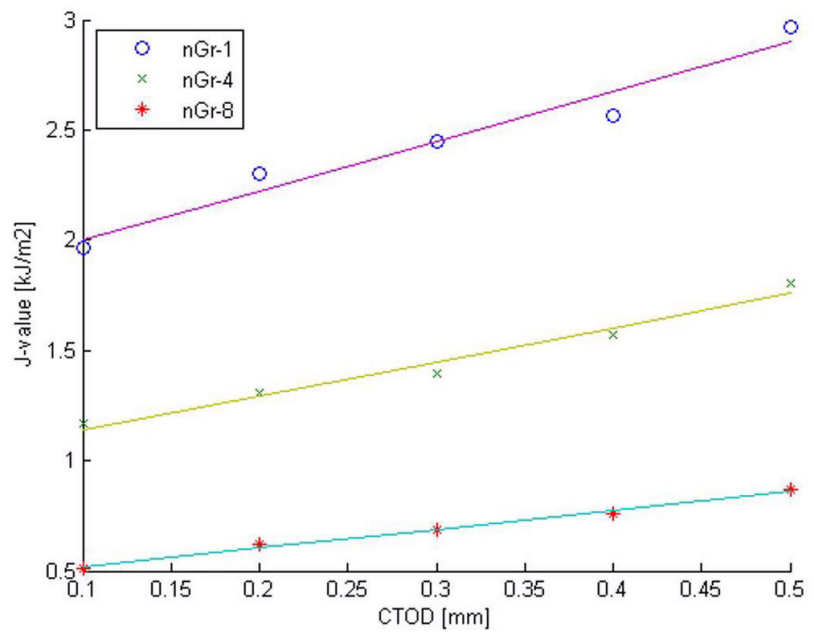

Fig. $4 J$ value vs CTOD curves

\subsection{Investigation of strain distribution}

Investigating the local performance of the material in the area near the crack tip can explain the fracture resistance properties of this material. The amplitude of vertical strain at the crack tip and its effect on the area around the crack are two factors used to explain the crack propagation tendency $[4,35-37]$. These two factors can be implemented utilizing the full-field displacement distribution acquired from the DIC technique $[13,38]$. The pre-cut crack length of $3 \mathrm{~mm}$ on the samples and ROI values of $5 \times 5 \mathrm{~mm}^{2}$ near the crack tip were compared. A series of photographs were taken with a Sony $\alpha 6000$ digital camera positioned to view the samples in cross-section. Photos were taken at $1 \mathrm{~s}$ intervals and until the elongation value of the specimens reached $100 \%$. The full-field displacement distribution obtained using Ncorr software is shown in Fig. 5. The point where the contours start to be parallel indicates the end of the effect of the vertical strain amplitude in the crack tip and the start of the pure shear area [39].

\subsection{The electrical properties}

The four-point probe method was used for the electrical resistance change in the samples during the static, quasi-static and cyclic tests. The experiments were carried out at $100 \mathrm{~mA}$ constant current and $10 \mathrm{~V}$ constant voltage. A constant current was fed from the outer probes of the sample using a constant DC source (Keithley Instruments Model 6221), and the resistance changes were recorded on the two probes on the inside. Images of the probe array are shown in Fig. 6. The voltage difference between the probes

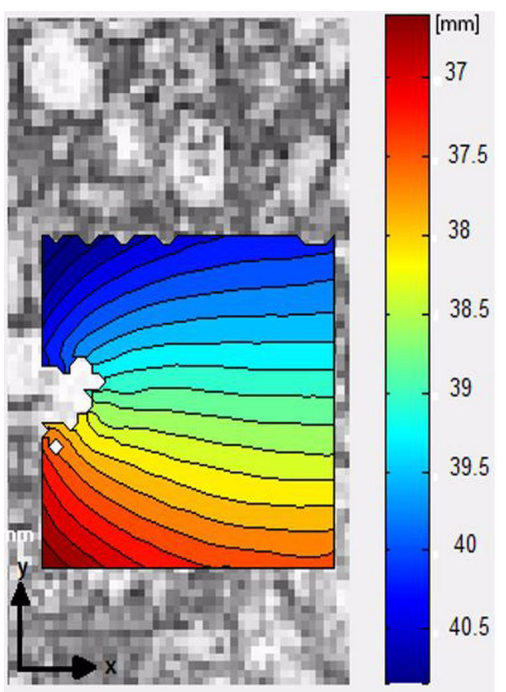

Fig. 5 The full-field displacement distribution ( $\mathrm{mm}$ ) in the area $5 \times 5 \mathrm{~mm}^{2}$ near the crack tip at a strain of $50 \%$ 


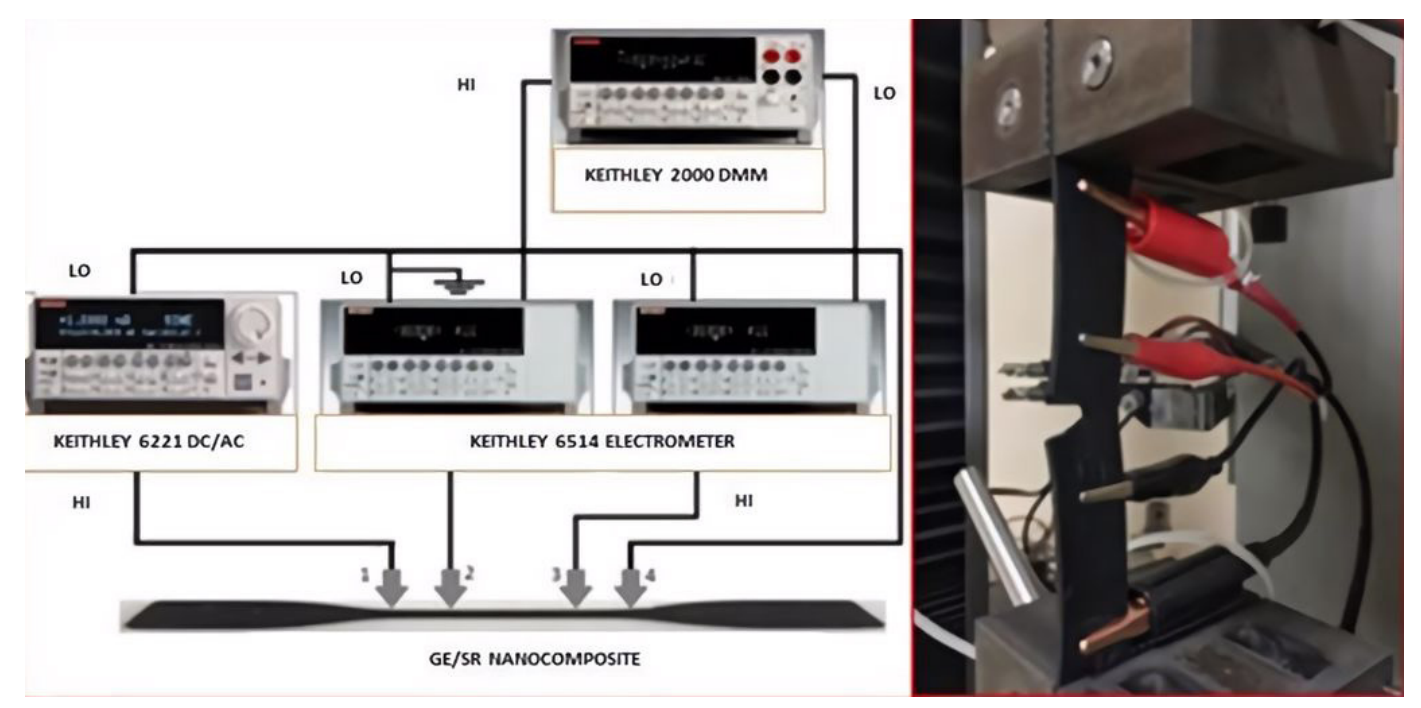

Fig. 6 Installing the probes and electrical sensing equipment

connected to the inner side was measured with Keithley Instruments Model 6514 branded electrometers. Data from both probes were recorded with LabVIEW using Keithley Instruments Model 2000, a digital multimeter.

The ends of the samples were wrapped with insulating tapes, minimizing the measurement errors caused by the surface tension that will occur on the sample surface during the resistance change and then connected to the fixing jaws of the measuring device. Data were recorded at $0.25 \mathrm{~s}$ intervals, and electrical resistance changes were determined based on Ohm's law. The electrical resistance change $\left(R_{a v}\right)$ is measured according to Eq. (3) based on the DC voltage and the current applied between the external probes:

$$
R_{a v}=\rho \frac{t}{A_{c}}
$$

where $R_{a v}(\Omega)$ is the measured electrical resistance of the composite samples, $t(\mathrm{~m})$ is the sample thickness, the cross-sectional area of the $A_{c}$ sample $\left(\mathrm{m}^{2}\right), \rho(\Omega \mathrm{m})$ is the resistivity of the composite materials, which indicates the strength to resist the flow of electric current.

$\sigma_{i}=\frac{1}{\rho}$

$\sigma_{i}(\mathrm{~S} / \mathrm{m})$ is the conductivity of the samples and is expressed in Eq. (4). The nGr-4 and nGr-8 samples were prepared for electrical resistance tests. The tests were carried out five times for each specimen, and average electrical resistance change values were used. The electrical resistance changes obtained by static tests were recorded under constant strain for constant strain and different crack lengths, while in quasi-static tests, the samples were stretched to the tear point. A novel method was used to measure electrical resistance. It was measured when the crack had been started propagating (when the CTOD was equal to $0.1 \mathrm{~mm})$, which made it sure that the Electrical Resistance $\left(\mathrm{R}_{\mathrm{op}}\right)$ corresponding to a certain propagating crack length (c) or opening CTOD- $R_{\text {op }}$ variation was recorded. The $\mathrm{R}_{\mathrm{op}}$ measurements for all pre-cut lengths of each sample were correlated with the change during crack propagation.

The precut sizes for nGrs samples are 1, 3, 5, 7, and $10 \mathrm{~mm}$. The precut measurements determined before the test were connected opened with the help of a surgical scalpel (blade thickness $0.45 \mathrm{~mm}$ ). After the specimens were mounted on the Zwick/Roell test machine, the strain was applied at a pull speed of $40 \mathrm{~mm} / \mathrm{min}, 5 \%, 10 \%, 15 \%$, and $20 \%$, respectively, in five cycles. No waiting was made in the sample during strain passages.

\section{Results and discussion}

\subsection{Vulcanizing and mechanical properties of $\mathbf{n G r}$ nanocomposites}

Hysteresis tests showed that the energy loss $(\Delta \mathrm{W})$ due to internal friction during the relaxation phase increased with the increase in the GE percentage.

The vulcanization properties of $\mathrm{nGr}$ nanocomposites are determined by vulcanization parameters such as Minimum Torque $\left(\mathrm{M}_{\mathrm{L}}\right)$, Maximum Torque $\left(\mathrm{M}_{\mathrm{H}}\right)$, Roasting Time $\left(T_{S 2}\right)$, Optimum Curing Time $\left(T_{90}\right)$. Here, $M_{L}$ is used to characterize the viscosity properties of the elastomer mixture, and $\mathrm{M}_{\mathrm{H}}$ is used to describe the shear modulus of the cured elastomer material. The difference between the maximum and minimum torque, $\Delta \mathrm{M}$, is expressed 
as the density resulting from the interaction between the matrix and filler materials [4]. $\mathrm{T}_{\mathrm{S} 2}$ and $\mathrm{T}_{90}$ represent curing start time and optimum curing time. In rheometer tests, it was observed that there was no significant change in roasting time $\left(\mathrm{t}_{\mathrm{S} 2}\right)$ and curing time $\left(\mathrm{T}_{90}\right)$. Table 2 shows the results of the rheometer and mechanical tests applied to nGr nanocomposites. Five measurements were made for the mechanical and rheometric tests on $\mathrm{nGr}$ nanocomposites. The values given in Table 2 are shown as the average of these measurements.

The $\mathrm{M}_{\mathrm{L}}$ values of $\mathrm{nGr}$ nanocomposites were higher than nGr- 0 . These values increased by $13.3 \%, 17.16 \%$ and $10.87 \%$ for $n G r-1, n G r-4, n G r-8$. The matrix viscosity increased due to the increase in $M_{L}$ value of nGr nanocomposites, and the $\mathrm{M}_{\mathrm{H}}$ value decreased in all. The increase in GE filler adversely affected the shear modulus due to local aggregation and uneven distribution in the matrix. The $\mathrm{T}_{\mathrm{S} 2}$ values of nanocomposites obtained by adding GE filler material to the mixtures are longer than $\mathrm{nGr}-0$. This situation is thought to delay the curing due to the low heat conduction caused by the large surface area due to the graphene sheets' shallow thickness and two-dimensional morphology and the absorption of accelerating agents by the GE platelets. $T_{90}$ values of GE-filled nanocomposites are longer than $\mathrm{nGr}-0$.

The density of nanocomposites varies depending on the interaction between the matrix material and the filler materials. The mixture's volumetric ratio of the filler and matrix material affects the density value. In addition, the air voids that will form in the matrix have a decreasing effect on the density of the mixture. Five different samples were taken from the lots of each nanocomposite compound, and their densities were measured, and the comparison was made by taking the average of the obtained values. The densities of nGr-1 and nGr-4 nanocomposites decreased by $0.81 \%$ and $0.73 \%$, respectively, compared to
nGr- 0 , while there was a $0.22 \%$ decrease in $n G r-8$. The standard deviation in the density measurements of nGr- 0 and nGr-1 is 0.0070 and 0.0029 , respectively. Depending on the filler amount, the standard deviation of nGr-4 and nGr-8 nanocomposite compounds changed to 0.0021 and 0.0020 . This situation indicates inhomogeneous distribution and aggregation of the filler material in the matrix. The hardness measurements were obtained by measurements made on five different samples, and their average values were calculated. The hardness of nanocomposite samples nGr-1, nGr-4, and nGr- 8 decreases by $2.22 \%$, $1.66 \%$, and $2.03 \%$, respectively, compared with the nGr-0 nanocomposite. The average hardness value of the nGr-o is 53.9 Shore A, which is the highest value compared to other samples. The standard deviation value in hardness measurements of nGr- 0 is 0.48 . nGr- $1, \mathrm{nGr}-4, \mathrm{nGr}-8$ nanocomposites were calculated as $0.38,0.42$ and 0.42 , respectively. The decrease in the standard deviation indicates that the hardness values are closer to the mean.

The five different samples were tested from each $\mathrm{nGr}$ nanocomposite in the tensile strength test, and the values obtained were averaged. As a result of the addition of GE filler material to the mixture, the tensile strength and elongation value decreased in all samples. Tensile strength and elongation at break values of nGr- $1, \mathrm{nGr}-4$, and nGr-8 nanocomposite samples decreased significantly compared to $\mathrm{nGr}-0$. The standard deviation value in tensile strength of nGr- 0 is 0.083 . nGr- $1, \mathrm{nGr}-4$, nGr- 8 nanocomposites were calculated as $0.143,0.239$ and 0.215 , respectively. The increase in the standard deviation indicates that the mechanical values are further away from the mean.

\subsection{SEM analysis}

SEM images of the microstructure investigation of graphene-filled rubber composites are shown in Fig. 7 ((a), (b), (c) and (d)).

Table 2 Materials' mechanical and rheometer properties

\begin{tabular}{|c|c|c|c|c|c|c|}
\hline \multirow{2}{*}{\multicolumn{2}{|c|}{ Properties }} & & \multicolumn{4}{|c|}{ Samples } \\
\hline & & & nGr-0 & nGr-1 & nGr-4 & nGr-8 \\
\hline \multicolumn{2}{|c|}{ Density } & {$\left[\mathrm{g} / \mathrm{cm}^{3}\right]$} & 1.1133 & 1.1043 & 1.1051 & 1.1108 \\
\hline \multicolumn{2}{|c|}{ Hardness } & [Shore A] & 53.9 & 52.7 & 53.0 & 52.8 \\
\hline \multirow{4}{*}{ 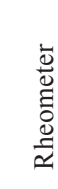 } & $M_{L}$ & {$[\mathrm{dNm}]$} & 1.69 & 1.95 & 2.04 & 2.05 \\
\hline & $\mathrm{M}_{\mathrm{H}}$ & {$[\mathrm{dNm}]$} & 13.26 & 12.78 & 13.24 & 12.92 \\
\hline & $\left(t_{\mathrm{s} 2}\right)$ & {$[\mathrm{min}]$} & 2.53 & 2.56 & 2.57 & 2.58 \\
\hline & $\left(\mathrm{t}_{90}\right)$ & {$[\mathrm{min}]$} & 5.34 & 5.38 & 5.39 & 5.35 \\
\hline \multicolumn{2}{|c|}{ Tensile strength } & {$[\mathrm{MPa}]$} & 16.25 & 14.67 & 14.51 & 13.33 \\
\hline \multicolumn{2}{|c|}{$\begin{array}{l}\text { Elongation at } \\
\text { break }\end{array}$} & {$[\%]$} & 610.94 & 548.83 & 493.46 & 593.63 \\
\hline \multicolumn{2}{|l|}{$\Delta \mathrm{W}$} & {$[\mathrm{Nmm}]$} & 11.625 & 11.773 & 11.800 & 12.253 \\
\hline
\end{tabular}




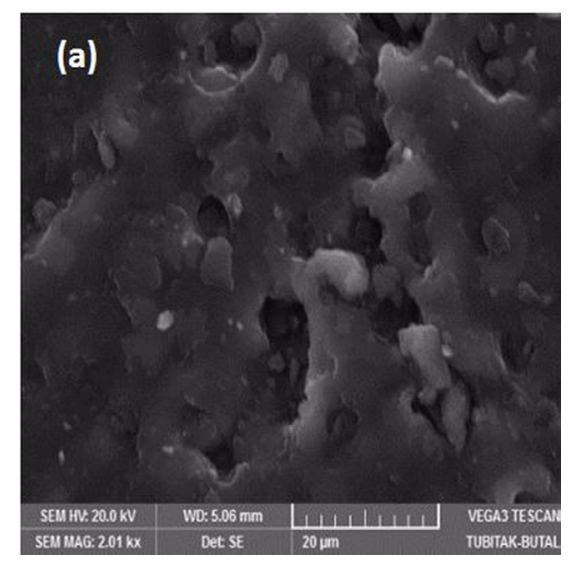

(a)

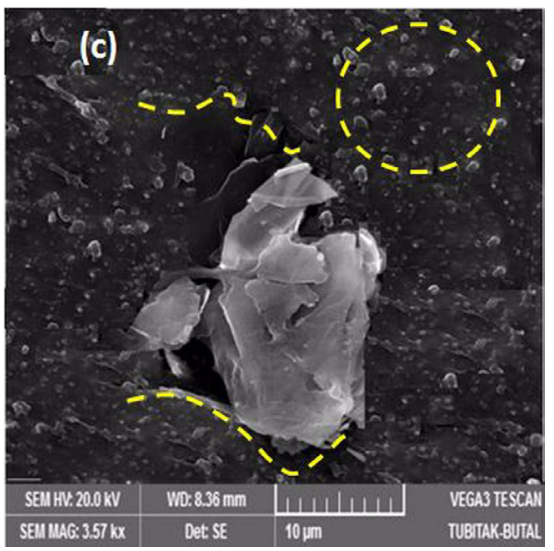

(c)

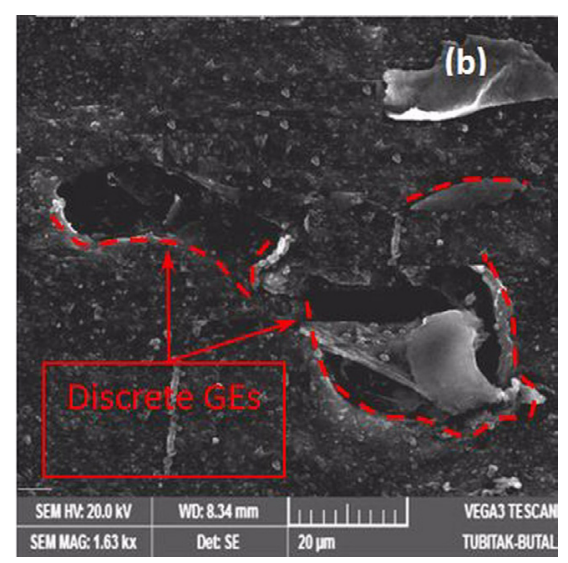

(b)

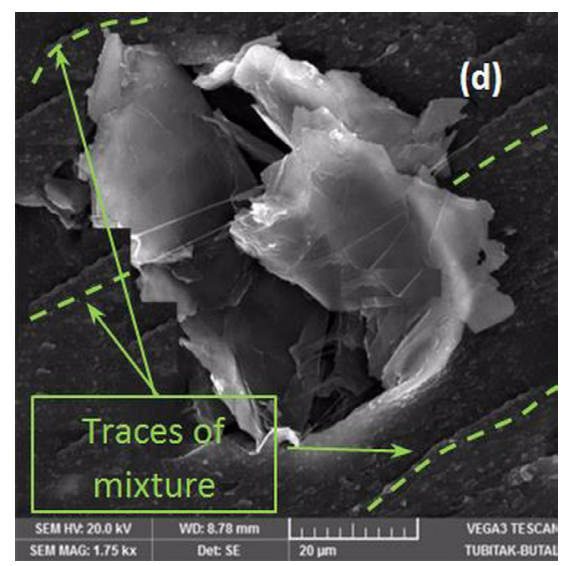

(d)

Fig. 7 SEM images of prepared GE/SR Rubber compounds: (a) CB filled mixture, (b) nGr-1, (c) nGr-4 and (d) nGr-8

The image shown in Fig. 7(a) belongs to the nGr-0 sample. It contains only carbon black at a filling ratio of 47.6 phr. Considering the shape of the carbon black fillings and the distance between them in the SEM image, it is seen that they are in different size clusters with a homogeneous distribution. Small particle sizes in the compound increase the interaction with the rubber matrix. The porous structure and local fractures formed in the material are considered obstacles in the charge transfer from polymer to carbon black during loading. In Fig. 7(b), (c), and (d), SEM images of the morphology of the mixtures reinforced with conductive Graphene nanoplatelets in different proportions are given. The photos contain errors such as matrix-stuck structures, broken geometries, and superimposed particles due to mixing preparation difficulties due to graphene's 2-dimensional structure. For example, when we examine the Fig. 7(b) image of the rubber mixture named nGr-1, pits and hillocks are found in the rubber matrix inner structure. The platelets were arranged in parallel in the topographic structure of the mixtures having a filler ratio of $1 \mathrm{phr}$. In some areas, the graphene layers interacted seamlessly with both rubber and carbon black, while in others, overlapping and spaced graphene layers were seen. This causes the material to show a high electrical resistance.

In Fig. 7(c), an SEM image of the nGr-4 mixture is given. Increasing the amount of GE filler increased the internal structure defects. It is seen that graphene flakes stick to the matrix in clusters, deforms, and deformations due to contact with each other. This situation can adversely affect charge and electron transfer. In addition, as the filler amount increases, the material will get hot due to mechanical friction. This situation made it difficult for the matrix and the filler to contact each other appropriately. This surface friction will cause both the surface deterioration of GE's and the formation of a thick layer by sticking with each other. This situation can be seen more clearly in Fig. 7(d). In addition, since the nGr-4 and nGr-8 mixtures will be more per unit volume in the rubber matrix, the transmission network formed by conductive fillings is more clearly seen in electrical tests. Therefore, determining the optimum ratio of the filler amount is 
extremely important for ease of process and improvement of the electrical and mechanical properties of the material. For this reason, studies have been carried out by selecting three different filler amounts. Increasing the filler ratio to $8 \mathrm{phr}$ revealed the fractures and layers in the matrix more clearly. GE nanoplatelets in the nGr-8 blend made it challenging to prepare the blend. Excessive curing occurred in the material due to the increasing temperature. This state was expected to affect both the mechanical and electrical properties adversely.

\subsection{The fracture resistance depending on the $J$-integral test}

The fracture resistance is discussed using the tear energy criterion based on $J_{I C}$ and $T_{R}$ values. Samples with a $3 \mathrm{~mm}$ pre-cut were used as comparison samples. It was observed that the $J_{I C}$ and $T_{R}$ values decreased with the increase of the graphene filler ratio. In other words, the inclusion of graphene platelets in the advanced mixture adversely affected the refractive performance of the samples, resulting in lower fracture resistance in the initial and propagation stages. The values obtained from the tests are given in Table 3 . It can be thought that this is due to the gaps caused by the stresses caused by the presence of graphene nanoplatelets [7] and the sharp edges that graphene has in its structure.

\subsection{The fracture resistance depending on the investigation of strain}

According to Dong et al. [4], more deformability near the crack tip causes a more dissipation of the local tearing energy, positively affecting fracture resistance in general. The results were acquired by full-field strain distribution near the crack tip at the strain of $100 \%$.

Table 4 gives the strain amplitudes at the crack tip and the crack area. Adding more graphene nanoplatelets to the mixture caused the length of the vertical strain amplitude affected area at the crack tip to shorten along the x-direction. Fig. 8 shows the local strain distribution near the crack tip along the $\mathrm{x}$-axis. The vertical strain amplitude became higher due to increasing the graphene filler ratio.

Table $3 T_{R}$ and $J_{I C}$ values during CTOD development from $0.1 \mathrm{~mm}$ to $0.5 \mathrm{~mm}$ for pre-cut of $5 \mathrm{~mm}$

\begin{tabular}{|c|c|c|c|c|c|c|}
\hline \multirow{2}{*}{$\begin{array}{l}\text { CTOD } \\
{[\mathrm{mm}]}\end{array}$} & \multicolumn{5}{|c|}{$J_{I C}$-value $\left[\mathrm{kJ} / \mathrm{m}^{2}\right]$} & \multirow{2}{*}{$\begin{array}{c}T_{R} \\
{[\mathrm{MPa}}\end{array}$} \\
\hline & 0.1 & 0.2 & 0.3 & 0.4 & 0.5 & \\
\hline nGr-1 & 1.97 & 2.3 & 2.45 & 2.56 & 2.96 & 2.26 \\
\hline nGr-4 & 1.17 & 1.3 & 1.4 & 1.57 & 1.81 & 1.54 \\
\hline nGr-8 & 0.51 & 0.62 & 0.69 & 0.76 & 0.87 & 0.86 \\
\hline
\end{tabular}

Table 4 Strain amplitudes in the crack tip and effect on the area

\begin{tabular}{lccc}
\hline Properties & & Samples \\
& nGr-1 & nGr-4 & nGr-8 \\
Strain amplitude $\left(\mathrm{E}_{\mathrm{yy}}\right)[\%]$ & 0.39 & 0.53 & 1.49 \\
Strain amplification effects $[\mathrm{mm}]$ & 1.92 & 1.89 & 1.66 \\
\hline
\end{tabular}

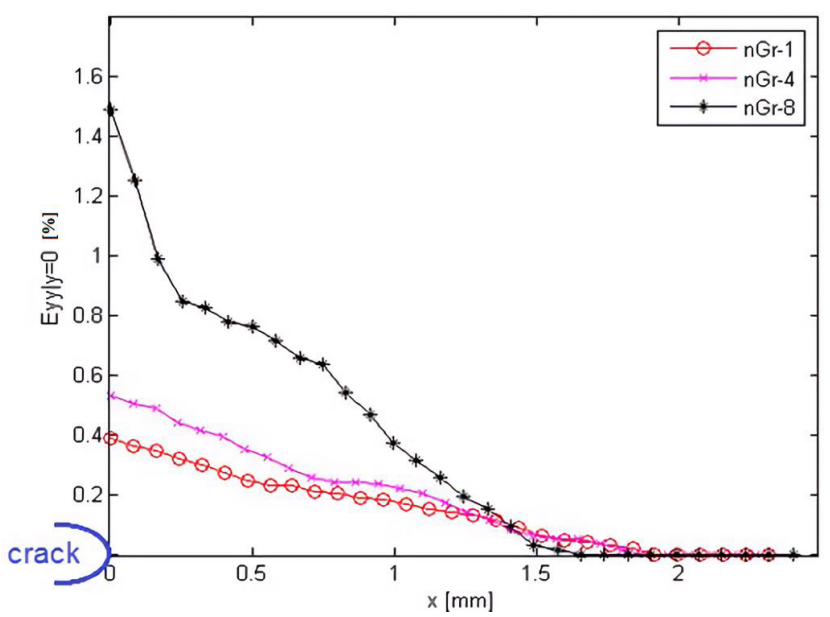

Fig. 8 The local strain distribution along the $x$-direction where $y=0$, $\mathrm{x}=0$ is considered as the crack tip location at the strain of $100 \%$ and pre-cut of $3 \mathrm{~mm}$

Thus, it was found that there is a greater concentration of stress in the area near the crack tip and more tendency to start tearing early.

\subsection{Strain energy density}

The stored strain energy density values of $3 \mathrm{~mm}$ pre-cut samples until the strain value reaches $100 \%$ are shown in Fig. 9 for samples prepared with different filler ratios. It showed that more graphene filler material stores more strain energy per unit volume. A considerable increase was observed in the amount of strain energy in the $8 \mathrm{phr}$ graphene-filled samples compared to the samples prepared with 1 phr and 4 phr fillers.

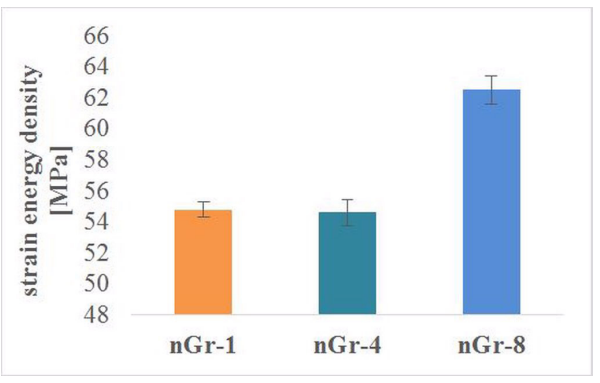

Fig. 9 Strain energy density stored up to strain of $100 \%$ of $3 \mathrm{~mm}$ pre-cut specimens 


\subsection{Electrical properties}

The electrical resistance values determined by the static test vary depending on the elongation amounts applied to the samples. It was observed that as the amount of elongation increased, the resistance change values increased with the increase in the distance between the graphene nanoplatelets in the matrix. The tests showed that the distance between the filler particles increases at $10 \%$ and above strain values, and the conductive mesh deteriorates. It has been observed that these samples behave like an insulating material due to their very high resistance values. The test results obtained are shown in Table 5.

Fig. 10 shows the electrical resistance change values graph depending on the crack length obtained from the quasi-static tests. The electrical property of nGr-1 was not drawn as it showed confusion in conductivity due to the weak presence of graphene. It has been observed that the electrical conductivity increases with increasing the amount of graphene filler.

The electrical resistance change due to the strain given in Fig. 11 occurred in three stages. The electrical resistance increased in step 1 due to the effect of strain, which led to an increase in the distance between nano graphene platelets. This distance between the conductive fillings

Table 5 Electrical resistance during the static test

\begin{tabular}{|c|c|c|c|c|c|c|}
\hline \multirow{2}{*}{\multicolumn{2}{|c|}{$\begin{array}{l}\text { Precut } \\
\text { length }[\mathrm{mm}]\end{array}$}} & \multicolumn{5}{|c|}{ Strain $(\%)$} \\
\hline & & $0 \%$ & $5 \%$ & $10 \%$ & $15 \%$ & $20 \%$ \\
\hline \multirow{4}{*}{ 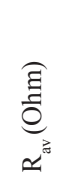 } & 0 & $3.20 \mathrm{E}+06$ & $3.59 \mathrm{E}+07$ & $(*)$ & $(*)$ & $(*)$ \\
\hline & 0.25 & $1.48 \mathrm{E}+07$ & $3.94 \mathrm{E}+07$ & $(*)$ & $(*)$ & $(*)$ \\
\hline & 0.5 & $9.08 \mathrm{E}+06$ & $3.96 \mathrm{E}+07$ & $(*)$ & $(*)$ & $(*)$ \\
\hline & 10 & $9.93 \mathrm{E}+06$ & $3.32 \mathrm{E}+07$ & $(*)$ & $(*)$ & $(*)$ \\
\hline
\end{tabular}

(*) Overflow

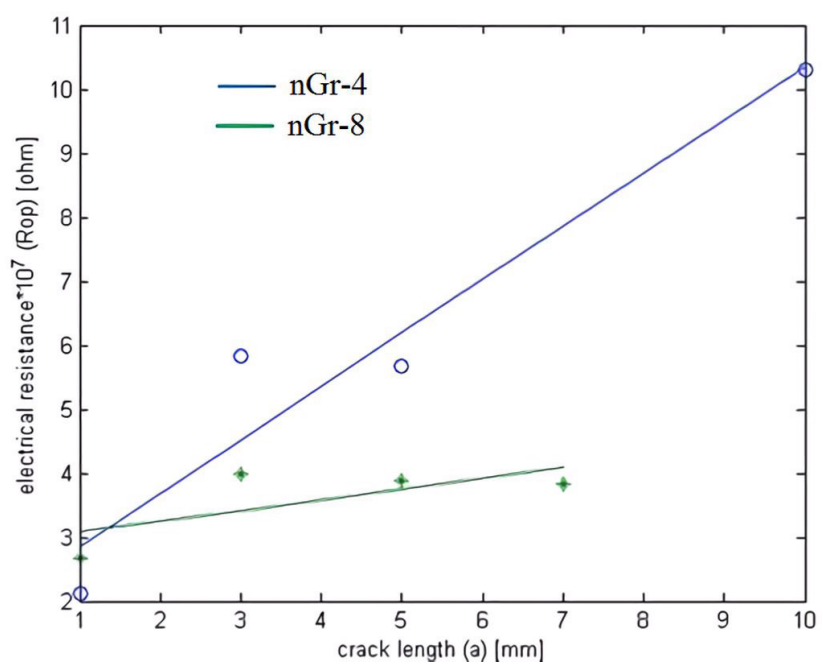

Fig. 10 The electrical resistance changing during the crack propagation

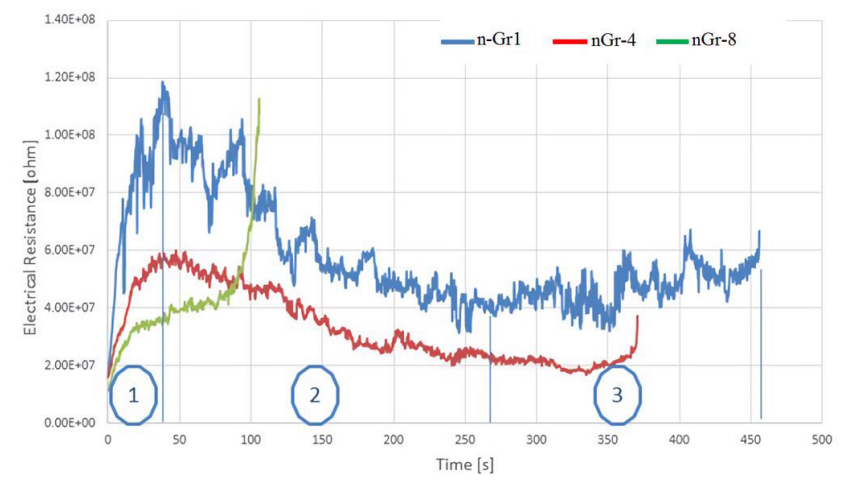

Fig. 11 Electrical resistance vs time curve during SENT

decreased in the $2^{\text {nd }}$ stage due to the conductive network formation. Moreover, in stage 3, the resistance turned upwards due to the narrowing section of the uncut area near the crack tip.

The electrical resistance change during crack propagation for each sample is shown in Table 6.

Fig. 12 shows the electrical resistance variation graphs of nGr-4 samples made of $1,3,5,7$, and $10 \mathrm{~mm}$ precut under cyclic loading. At the end of the strains applied to the sample with a precut amount of $1 \mathrm{~mm}$, the average electrical resistance change value was measured as $2.15 \mathrm{E}+07 \mathrm{Ohm}$. Likewise, in samples with precut amounts of $3,5,7$, and $10 \mathrm{~mm}$, the average resistance value was measured as 2.44E+07 Ohm, 4.93E+07 Ohm, 7.93E+07 $\mathrm{Ohm}$, and $1.09 \mathrm{E}+08 \mathrm{Ohm}$, respectively.

The increase in the electrical resistance change in the samples occurs due to the separation of the GEs in the matrix due to the applied strain increase and the deterioration of the conduction network in the structure. As the amount of precut increases, the cross-sectional area of the sample decreases, so the electrical resistance of the sample increases according to Eq. (3). Dynamic electrical resistance measurement tests confirm this.

Fig. 13 shows the change of electrical resistance and precut distance depending on the strain.

\section{Conclusion}

Based on the results of this research, the following conclusions can be stated:

1. Increasing the conductive filler in rubber blends reduces the $J_{I C}$ and $T_{R}$ values, i.e., the reduction in crack propagation and initiation resistance.

2. The results acquired from investigating the vertical strain distribution near the crack tip showed an increment of the strain amplitude and decremented in the affected area near the crack tip. 
Table 6 The electrical resistance during crack propagation

\begin{tabular}{lccccc}
\hline Pre-cut & \multicolumn{5}{c}{ Average Electrical Resistance $[\Omega]$} \\
length $[\mathrm{mm}]$ & 1 & 3 & 5 & 7 & 10 \\
$\mathrm{nGr}-1$ & $1.01 \mathrm{E}+08$ & $2.12 \mathrm{E}+07$ & $9.59 \mathrm{E}+07$ & $(*)$ & $(*)$ \\
$\mathrm{nGr}-4$ & $2.12 \mathrm{E}+07$ & $5.84 \mathrm{E}+07$ & $5.67 \mathrm{E}+07$ & $(*)$ & $1.03 \mathrm{E}+08$ \\
$\mathrm{nGr}-8$ & $2.67 \mathrm{E}+07$ & $3.89 \mathrm{E}+07$ & $3.88 \mathrm{E}+07$ & $3.82 \mathrm{E}+07$ & $(*)$ \\
\hline
\end{tabular}

(*) Overflow

(a) $\mathrm{nGr}-4$ / Precut $=1 \mathrm{~mm}$

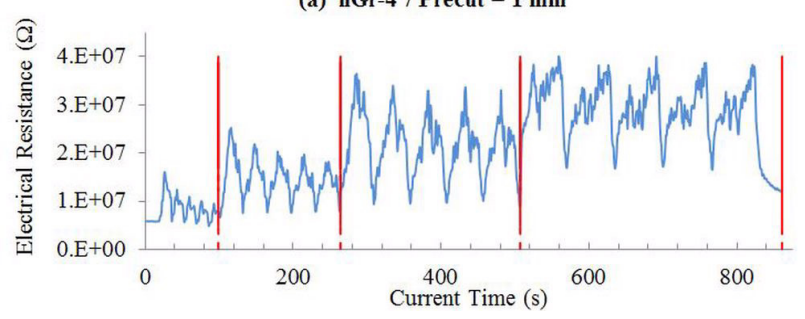

(a)

(c) $\mathbf{n G r}-4$ / Precut $=5 \mathrm{~mm}$

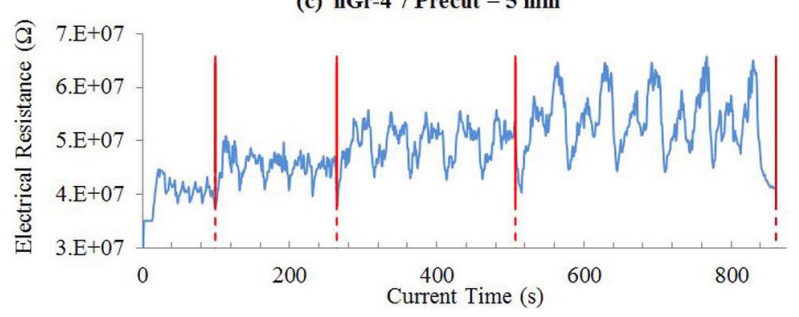

(c)

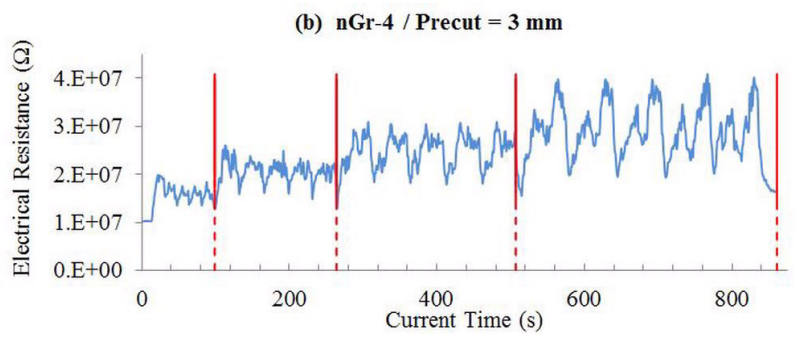

(b)

(d) $\mathrm{nGr}-4$ / Precut $=7 \mathrm{~mm}$

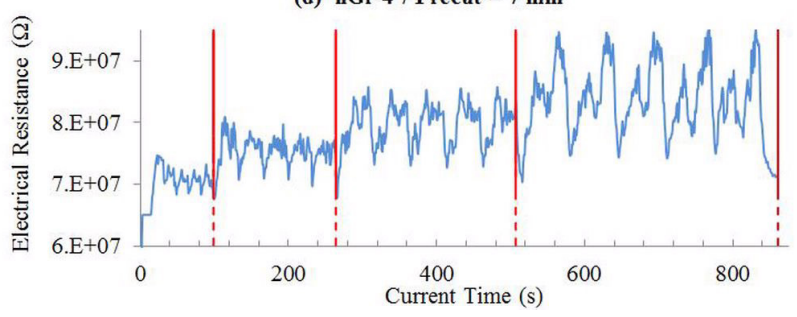

(d)

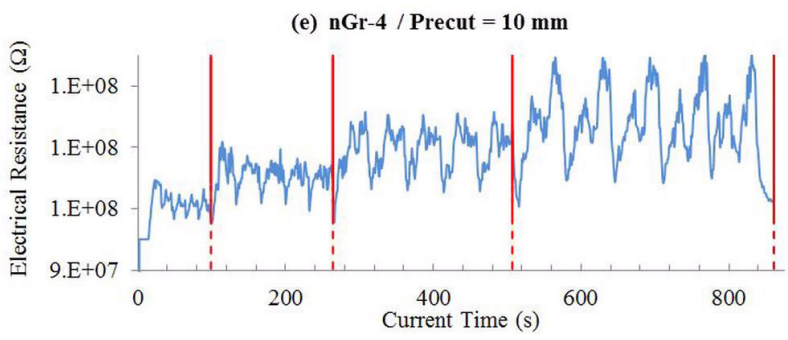

(e)

Fig. 12 Electrical resistance vs time curve during the dynamic test and several pre-cut lengths, (a) $1 \mathrm{~mm}$, (b) $3 \mathrm{~mm}$, (c) $5 \mathrm{~mm}$, (d) $7 \mathrm{~mm}$, (e) $10 \mathrm{~mm}$

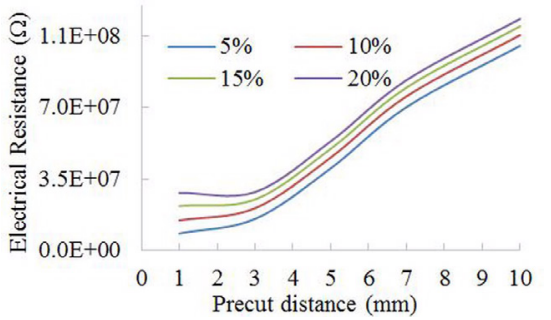

Fig. 13 Change of electrical resistance and precut distance depending on the strain

3. The strain energy density values are stored until the strain value of the samples reached $100 \%$ indicating that more graphene filler material stores more strain energy per unit volume.
4. A significant increase in strain energy was observed in the 8 phr graphene-filled samples compared to those prepared with $1 \mathrm{phr}$ and 4 phr fillers.

5. $J_{I C}$ and $T_{R}$ cause an increase in stress concentration and a decrease in fracture resistance in the cross-section of the uncut area near the crack tip.

6 . The electrical properties connected to the conductive network formed by the conductive filler material increased depending on the GE filler ratio.

7. The sensibility was fallen when GE's percentage rise to $8 \mathrm{phr}$ according to the state of $4 \mathrm{phr}$, causing hardness for crack growth tracking by the corresponding electrical resistance value. 


\section{Acknowledgment}

This work was funded by Pega Automotive Trade Co. The authors would like to thank the staff of the R\&D center

\section{References}

[1] Rivlin, R. S, Thomas, A.G. ""Rupture of rubber. I. Characteristic energy for tearing", Journal of Polymer Science, 10(3), pp. 291-318, 1953.

$$
\text { https://doi.org/10.1002/pol.1953.120100303 }
$$

[2] Kazakeviciute, J., Rouse, J. P., Focatiis, D., Hyde, C. "Small specimen techniques for estimation of tensile, fatigue, fracture and crack propagation material model parameters", The Journal of Strain Analysis for Engineering Design, 2021.

https://doi.org/10.1177/03093247211025208

[3] Griffith, A. A. "VI . The phenomena of rupture and flow in solids", Philosophical Transactions of the Royal Society A, Mathematical, Physical and Engineering Sciences, 221(582-593), pp. 163-198, 1921.

https://doi.org/10.1098/rsta.1921.0006

[4] Dong, B., Liu, C., Wu Y. P. "Fracture and fatigue of silica/carbon black/natural rubber composites”, Polymer Testing, 38, pp. 40-45, 2014.

https://doi.org/10.1016/j.polymertesting.2014.06.004

[5] Agnelli, S., Ramorino, G., Passera, S., Karger-Kocsis, K., Riccò, T. "Fracture resistance of rubbers with MWCNT, organoclay, silica and carbon black fillers as assessed by the J-integral: Effects of rubber type and filler concentration", eXPRESS Polymer Letters, 6(7), pp. 581-587, 2012.

https://doi.org/10.3144/expresspolymlett.2012.61

[6] Yan, N., Xia, H., Zhan, Y., Fei, G. "New Insights into Fatigue Crack Growth in Graphene-Filled Natural Rubber Composites by Microfocus Hard-X-Ray Beamline Radiation", Macromolecular Materials and Engineering, 298(1), pp. 38-44, 2013. https://doi.org/10.1002/mame.201200044

[7] Dong, B., Liu, C., Lu, Y., Zhang, L., Wu, Y. "Effects of hybrid filler networks of carbon nanotubes and carbon black on fracture resistance of styrene-butadiene rubber composites", 56(12), pp. 1425-1431, 2016.

https://doi.org/10.1002/pen.24379

[8] Song, Y., Yu, J., Yu, L., Alam, F. E., Dai, W., Li, C., Jiang N. "Enhancing the thermal, electrical, and mechanical properties of silicone rubber by addition of graphene nanoplatelets", Materials \& Design, 88, pp. 950-957, 2015. https://doi.org/10.1016/j.matdes.2015.09.064

[9] Liu, M., Guo, J., Hui, C. Y., Zehnder, A. T. "Application of Digital Image Correlation (DIC) to the Measurement of Strain Concentration of a PVA Dual-Crosslink Hydrogel Under Large Deformation", Experimental Mechanics, 59(7), pp. 1021-1032, 2019.

https://doi.org/10.1007/s11340-019-00520-4

[10] Rossi, M., Cortese, L., Genovese, K., Lattanzi, A., Nalli, F., Pierron, F. "Evaluation of Volume Deformation from Surface DIC Measurement", Experimental Mechanics, 58(7), pp. 1181-1194, 2018.

https://doi.org/10.1007/s11340-018-0409-0 for providing the use of composite samples and test equipment necessary for the experiments.

[11] Le Cam, J. B., Huneau, B., Verron, E. "Fatigue damage in carbon black filled natural rubber under uni- and multiaxial loading conditions", International Journal of Fatigue, 52, pp. 82-94, 2013. https://doi.org/10.1016/j.ijfatigue.2013.02.022

[12] Li, L., Gong, M., Chui, Y. H., Schneider, M., Li, D. "Measurement of the elastic parameters of densified balsam fir wood in the radial-tangential plane using a digital image correlation (DIC) method", Journal of Materials Science, 48(21), pp. 7728-7735, 2013.

https://doi.org/10.1007/s10853-013-7593-1

[13] Zhang, Y., Karnati, S., Pan, T., Liou, F. "Determination of constitutive relation from miniature tensile test with digital image correlation", The Journal of Strain Analysis for Engineering Design, 55(3-4), pp. 99-108, 2020. https://doi.org/10.1177/0309324719892732

[14] Wang, H., Xie, H., Wu, L., He, S. "Study on the effect of DIC deformation sensor on mechanical property of substrate", Measurement, 49, pp. 283-288, 2014.

https://doi.org/10.1016/j.measurement.2013.12.006

[15] Behroozinia, P., Mirzaeifar, R., Taheri, S. "A review of fatigue and fracture mechanics with a focus on rubber-based materials", Proceedings of the Institution of Mechanical Engineers, Part L: Journal of Materials: Design and Applications, 233(5), pp. 1005-1019, 2019. https://doi.org/10.1177/1464420717719739

[16] Craig, W. D., Van Leeuwen, F. B., Jarrett, S. R., Hansen, R. S., Berke, R. B. "Using text as a native speckle pattern in digital image correlation", The Journal of Strain Analysis for Engineering Design, 2021. https://doi.org/10.1177/03093247211045602

[17] Blaber, J., Adair, B., Antoniou, A. "Ncorr: Open-Source 2D Digital Image Correlation Matlab Software", Experimental Mechanics, 55(6), pp. 1105-1122, 2015.

https://doi.org/10.1007/s11340-015-0009-1

[18] Harilal, R., Ramji, M. "Adaptation of Open Source 2D DIC Software Ncorr for Solid Mechanics Applications", In: 9th International Symposium on Advanced Science and Technology in Experimental Mechanics, New Delhi, India, 2014, pp. 1-6. https://doi.org/10.13140/2.1.4994.1442

[19] Vozniakovskii, A. A., Vozniakovskii, A. P., Kidalov, S. V., Otvalko, J., Yu Neverovskaia, A. "Characteristics and mechanical properties of composites based on nitrile butadiene rubber using graphene nanoplatelets", Journal of Composite Materials, 54(23), pp. 3351-3364, 2020. https://doi.org/10.1177/0021998320914366

[20] Kasım, H., Yazıc1, M. "Electrical Properties of Graphene / Natural Rubber Nanocomposites Coated Nylon 6.6 Fabric under Cyclic Loading", Periodica Polytechnica Chemical Engineering, 63(1), pp. 160-169, 2019. https://doi.org/10.3311/PPch.12122 
[21] ASTM International "ASTM D471-12 Standard Test Method for Rubber Property-Effect of Liquids", ASTM International, West Conshohocken, PA, USA, 1995.

https://doi.org/10.1520/D0471-12

[22] ASTM International "ASTM D395-18 Standard Test Methods for Rubber Property-Compression Set", ASTM International, West Conshohocken, PA, USA, 2018.

https://doi.org/10.1520/D0395-18

[23] Wang, H., Xie, H., Li, Y., Zhu, J. "Fabrication of micro-scale speckle pattern and its applications for deformation measurement", Measurement Science and Technology, 23(3), Article number: 035402, 2012

https://doi.org/10.1088/0957-0233/23/3/035402

[24] Ma, Y. J., Yao, X. F., Wang, D. "Experimental investigation on mechanical properties of CNT film using digital speckle correlation method", Optics and Lasers in Engineering, 50(11), pp. 1575-1581, 2012.

https://doi.org/10.1016/j.optlaseng.2012.05.023

[25] ASTM International "ASTM D5289-19a Standard Test Method for Rubber Property—Vulcanization Using Rotorless Cure Meters", ASTM International, West Conshohocken, PA, USA, 2019. https://doi.org/10.1520/D5289-19A

[26] ASTM International "ASTM D297-15 Standard Test Methods for Rubber Products-Chemical Analysis", ASTM International, West Conshohocken, PA, USA, 2019 https://doi.org/10.1520/D0297-15

[27] ASTM International "ASTM D2240-00 Standard Test Method for Rubber Property-Durometer Hardness", ASTM International, West Conshohocken, PA, USA, 2017. https://doi.org/10.1520/D2240-00

[28] ASTM International "ASTM D412-15 Standard Test Methods for Vulcanized Rubber and Thermoplastic Elastomers-Tension", ASTM International, West Conshohocken, PA, USA, 2016. https://www.doi.org/10.1520/D0412-15

[29] Kasim, H., Aldeen, A. N., Can, Y., Yazici, M. "Investigation of the Crack Propagation Behavior of the Multiwalled Carbon Nanotube/ Graphite/Natural Rubber Hybrid Nanocomposites Using Digital Image Correlation Technique", Journal of Nanoelectronics and Optoelectronics, 14(12), pp. 1766-1770, 2019. https://doi.org/10.1166/jno.2019.2675

[30] Legorju-jago, K., Bathias, C. "Fatigue initiation and propagation in natural and synthetic rubbers", International Journal of Fatigue, 24(2-4), pp. 85-92, 2002.

https://doi.org/10.1016/S0142-1123(01)00062-7
[31] Weng, G., Huang, G., Lei, H., Qu, L., Nie, Y., Wu, J. "Crack initiation and evolution in vulcanized natural rubber under high temperature fatigue", Polymer Degradation and Stability, 96(12), pp. 2221-2228, 2011. https://doi.org/10.1016/j.polymdegradstab.2011.09.004

[32] Lee, D., Tippur, H., Kirugulige, M., Bogert, P. "Experimental Study of Dynamic Crack Growth in Unidirectional Graphite/ Epoxy Composites Using Digital Image Correlation Method and High-speed Photography", Journal of Composite Materials, 43(19), pp. 2081-2108, 2009. https://doi.org/10.1177/0021998309342139

[33] Hu, Z. X., Xu, T. G., Wang, X. M., Xie, Z. M., Luo, H. Y., He, Y., Guo, L., Li, Y. P., Gan, R. Z., Lu, H. B. "Fluorescent digital image correlation techniques in experimental mechanics", Science China Technological Sciences, 61(1), pp. 21-36, 2018. https://doi.org/10.1007/s11431-017-9103-8

[34] Gu, X., Liang, Y., Fu, S. "Evaluation and optimization of digital image correlation processing variables using genetic algorithm", The Journal of Strain Analysis for Engineering Design, 51(6), pp. 408-415, 2016. https://doi.org/10.1177/0309324716645704

[35] Sharma, A. P., Khan, S. H., Parameswaran, V. "Response and failure of fiber metal laminates subjected to high strain rate tensile loading", Journal of Composite Materials, 53(11), pp. 1489-1506, 2019. https://oi.org/10.1177/0021998318804620

[36] Baldassarre, A., Ocampo, J., Martinez, M., Rans, C. "Accuracy of strain measurement systems on a non-isotropic material and its uncertainty on finite element analysis", The Journal of Strain Analysis for Engineering Design, 56(2), pp. 76-95, 2021. https://doi.org/10.1177/0309324720924580

[37] Rupil, J., Roux, S., Hild, F., Vincent, L. "Fatigue microcrack detection with digital image correlation", The Journal of Strain Analysis for Engineering Design, 46(6), pp. 492-509, 2011. https://doi.org/10.1177/0309324711402764

[38] Chen, Y., Song, X., Ji, C., Wang, F. "Characterizing the damage behavior of thin sheets for fuselage based on in situ corrosion fatigue test and digital image correlation technique", International Journal of Damage Mechanics, 30(3), pp. 399-414, 2021 https://doi.org/10.1177/1056789520962828

[39] Mzabi, S., Berghezan, D., Roux, S., Hild, F., Creton, C. "A critical local energy release rate criterion for fatigue fracture of elastomers", Journal of Polymer Science: Part B Polymer Physics, 49(21), pp. 1518-1524, 2011 https://doi.org/10.1002/polb.22338 